\title{
Preface: Land Surface Processes and Interactions-From HCMM to Sentinel Missions and Beyond
}

\author{
Zhongbo Su ${ }^{1, *}$, Zoltán Vekerdy ${ }^{1,2}$ and Yijian Zeng ${ }^{1}$ \\ 1 Department of Water Resources, Faculty of Geo-Information Science and Earth Observations (ITC), \\ University of Twente, Hengelosestraat 99, 7514 AE Enschede, The Netherlands; z.vekerdy@utwente.nl or \\ vekerdy.zoltan@mkk.szie.hu (Z.V.); y.zeng@utwente.nl (Y.Z.) \\ 2 Department of Water Management, Faculty of Agricultural and Environmental Sciences, \\ Szent István University, Páter Károly u. 1., 2100 Gödöllő, Hungary \\ * Correspondence: z.su@utwente.nl
}

Academic Editor: Prasad S. Thenkabail

Received: 27 July 2017; Accepted: 27 July 2017; Published: 31 July 2017

\section{Introduction}

The scientific understanding of the energy and water fluxes between land and atmosphere primarily predicates our capacity to describe, model, and predict the highly complex Earth system, which is formed by mutually interlinked components (land, atmosphere, and ocean). A credible representation of land surface processes and interactions, including energy, mass and momentum fluxes, as well as biogeochemical cycles, in Earth System Models (ESMs) is crucially important.

Recognizing the importance to better understand these complex processes and interactions, the World Climate Research Programme (WCRP) launched the Global Energy and Water Cycle Experiment (GEWEX) in 1990, which has been currently evolved into Phase III as Global Energy and Water Exchanges (GEWEX), with its mission to measure and predict global and regional energy and water variations, trends, and extremes, via improved observations and modelling of land, atmosphere, and their interactions [1].

Tremendous efforts have been devoted to Earth observations (i.e., remote sensing and in situ sensing) of land-atmosphere interface characteristics, including heat fluxes, soil moisture, land and sea surface temperature, precipitation, snow, and vegetation, as boundary conditions for climate modelling studies. One of the pioneering satellite missions was the Heat Capacity Mapping Mission (HCMM), which was an experimental satellite program launched on 26 April 1978, to observe simultaneously reflected solar radiation and emitted thermal radiation in its visible and infrared channels, respectively, either during the day or at night [2]. HCMM was the first cooperation project between the United States and Europe in the field of space-borne remote sensing [3]. These pioneer efforts were primarily scientific, to lay the foundations for later practical applications of satellite imaging technologies.

More recently, a new fleet of satellite constellations called Sentinels, particularly designed for the Copernicus programme (previously known as Global Monitoring for Environment and Security (GMES) services), includes radar and multi-spectral imaging instruments, meeting various observational needs for Essential Climate Variables (ECVs) for land, ocean, and atmosphere, as well as the interactions between them [4]. The aim of this fleet is to provide systematic data services for value-added products, based on the progress of Earth observation science.

\section{Recent Advances in Monitoring Land Surfaces and Interactions}

This special issue is a collection of recent advances in using multi-sensor data for monitoring land surfaces and interactions. The following aspects are addressed. 


\subsection{Drought Detection}

Drought has wreaked havoc on human societies throughout history, leading to fatal disasters including devastated crops, famine, conflicts, and wars. The occurrence of drought has been associated with climatic shifts that caused low rainfall, while being distinguished as meteorological, soil moisture, and hydrological drought, depending on the dominant controlling factors from the climatic perspective [5,6]. Many remote sensing-based indices have been developed in past decades to describe different aspects of droughts, while most of them neglect the changes in total water storage in an area and can result in certain bias. An integrated approach, not only considering the water and energy cycles but also the biogeochemical cycle, is needed to achieve a holistic view of the mechanisms behind drought occurrence.

Bayat et al. [7] used spectroscopic techniques and radiative transfer model (RTM) inversion to monitor the response to drought stress in a Poa pratensis (or meadow grass) canopy exposed to various levels of soil moisture deficit. The canopy reflectance and destructive measurements of LAI (Leaf Area Index) and leaf chlorophyll content (Cab) were taken. They found that spectroscopic techniques can reveal plant stress up to six days earlier than visual inspection. Furthermore, with the RTM model inversion by means of an iterative optimization approach, they found that the first strong sign of water stress on the retrieved grass properties was detected as a change of leaf water content, followed by $\mathrm{Cab}$ and leaf dry matter content in the earlier stages. The results from this study indicate the potentials of combining spectroscopic techniques and RTM model inversion to detect vegetation stress before they become visibly apparent, potentially contributing to an effective early warning system for drought detection.

Wang et al. [8] investigated the corn response to climate stress via identifying the NDVI (Normalized Difference Vegetation Index) residual, which was derived by using the concept of "normal" phenology over a decade. They found a significant relationship between crop yield and NDVI residual during the pre-silking period. The latter was deemed as the indicator to reflect crop stress during the early growing stage, as well as the early in-season yield prediction. They concluded that dry weather may hamper potential crop growth, while the oversupply of rainfall at the end of the growing season does not contribute to crop growth. However, the above-normal precipitation earlier in the growing season does reduce the risk of yield loss at the watershed scale, indicating a potential agriculture management strategy for adapting to the projected increase in periods of extreme droughts.

Exploring a new approach to estimate the time lag between anomalies in precipitation and vegetation activity, Van Hoek et al. [9] investigated the spatial distribution of the differences of the time lags between a wet year and a dry year in a drought-prone region of China. They used the phase spectrum of the cross-spectral density to measure the time lag in the response of vegetation activity to precipitation. This cross-spectral analysis approach can simultaneously determine the strength of the relationship and the phase lag for all significant periodic components. These results provide useful insights on vegetation response to precipitation as well as additional information for areas which are more susceptible to drought, particularly considering that drought usually originates from a lack of sufficient precipitation. The developed novel method can be applied to estimate the time lag between time series of satellite observations capturing paired forcing and response signals, in addition to providing useful information to improve early drought detection.

Using SPOT-5 Take-5 (as a proxy of Sentinel-2), Navarro et al. [10] investigated the complementarity and interoperability of optical and synthetic aperture radar (SAR) data for crop parameter retrieval and crop type classification, with a focus on crop water requirements. The crop parameter includes the basal crop coefficient $K_{c b}$ values and the length of the crop's development stages. The combined optical and microwave images provide useful information on qualitative and quantitative land cover changes, supporting land cover monitoring in different agriculture scenarios, with enhanced temporal resolution for agricultural applications. The determined $K_{c b}$ was used to compute the crop's evapotranspiration and to subsequently estimate the crop irrigation requirements based on a soil water balance model. They concluded that optical data can be replaced by microwave 
data in the presence of cloud cover. Unfortunately, lack of data for a part of the growing season made it impossible to properly identify each stage of the crop cycle.

\subsection{Surface Energy Fluxes}

The GEWEX LandFlux evaluation [11] indicates various systematic errors (e.g., induced by different considerations of model structures/physical processes) in the existing evaporation models, and it calls for caution in using a single model for any large-scale evaluation of the water cycle (e.g., components of which are mainly produced/investigated separately). Similar conclusions were also derived by the GEWEX radiative flux assessment, which attributes the patterns of disagreement among the flux products to ancillary data differences (e.g., atmospheric temperature-humidity, surface temperature, aerosols, etc.). The aforementioned discrepancy issues can be further exaggerated at the regional scale, where the appropriate land surface parameterization may differ dramatically over different biomes and climates [12-14]. The following papers in this special issue discussed some of these challenges.

Faivre et al. [15] introduced a Digital Surface Model (DSM) in a Computational Fluid Dynamics (CFD) Model to reproduce 3D wind fields, and to invert them for retrieving a spatialized surface roughness length for momentum $\left(Z_{0 m}\right)$. It was found that The DSM-CFD approach can estimate the roughness length well, similar to Brutsaert-based models [16], according to the estimated heat fluxes at the footprint scale. They claimed that for regional application, the likely uncertainty of the roughness information will be significant, as most NWP (Numerical Weather Prediction) models use land cover classification combined with phenological data to estimate the roughness length.

To account for the impact of topography on the spatial distribution of the solar radiative budget, Roupioz et al. [17] used the observed surface and atmosphere properties and topography to derive high temporal and spatial resolution solar radiative fluxes over the Tibetan Plateau (i.e., daily at $1 \mathrm{~km}$ resolution). The validation showed that, although the solar radiation estimates are satisfying in clear sky conditions, the algorithm is less reliable under cloudy sky conditions. Furthermore, it was found that the albedo product used has a too coarse temporal resolution and is therefore not accurate enough over rugged terrain.

The topography also controls the distribution of land surface temperature (LST), as well as the relationship between LST and near-surface air temperature (Ta, 1.5-2 $\mathrm{m}$ above surface). Lin et al. [18] parameterized the physiographic variables based on the terrain relief into a Ta estimation algorithm using both Terra and Aqua MODIS LST. Before taking into account the physiographic features, they concluded that the Terra nighttime LST has a strong linear relationship with Ta, especially for flat terrain areas, while in mountainous areas the relationship differed significantly from a simple linear correlation. After considering the topographic effect, as well as seasonal vegetation cover, altitudinal gradient, and the ambient absolute humidity, the accuracy of deriving Ta from LST was substantially improved. These results indicated that the relevant environmental factors must be considered when interpreting the spatiotemporal variation of the surface energy flux over complex topography.

Aerosol Optical Depth (AOD) is of importance for understanding the Earth radiation budget. Wu et al. [19] investigated the sensitivity of AOD to aerosol vertical profile and type, using the MODIS collection 6 algorithm over land. The results show that the AOD retrieval is highly sensitive to aerosol vertical profile and type. Errors in aerosol type assumption in the algorithm can lead to errors of up to $8 \%$ in the AOD retrieval, while the interplay effect can contribute to errors over $6 \%$. They concluded that more attention should be paid to the case of the air pollutions caused by forest fires or extreme dust events, in order to improve the AOD retrieval.

The evaporation flux over water bodies can be influenced by water salinity significantly, as salinity affects the density of water and the latent heat of vaporization. To take into account the influence of water salinity on the evaporation rate, Abdelrady et al. [20] adapted the SEBS (Surface Energy Balance System) model for large water bodies (AquaSEBS) via parameterizing the water heat flux (the analogy of ground heat flux over water) and the sensible heat flux by adapting the roughness heights 
for momentum and heat transfer. Furthermore, they introduced a salinity conversion factor over saline water bodies. The verification of AquaSEBS over Lake Ijsselmeer (the Netherlands) as well as Victoria and Tana freshwater lakes (Africa) showed that the calculated latent heat fluxes agree well with eddy covariance measurements. The comparison with ECMWF (European Centre for Medium-Range Weather Forecasts) data showed that the salinity reduced the evaporation by up to $27 \%$ in the Great Salt Lake and by $1 \%$ in Open Ocean. These findings indicate the importance of salinity to the evaporation rate and the suitability of the AquaSEBS for fresh and saline waters.

\subsection{Water Cycle and Climate from Space}

Satellite remote sensing (SRS) has provided major advances in understanding the water, energy, and carbon cycles, and through this, the understanding of the climate system and its change. In particular, SRS has contributed significantly to the generation of Essential Climate Variables (ECVs) for addressing the closure of the aforementioned three climate cycles. Closing the cycles allows us to identify gaps and where the SRS ECVs contribute to the fundamental understanding of the natural processes. This subsequently supports the improvement of forecasting climate change impacts. On the other hand, closing the cycles through SRS observation remains an outstanding scientific issue that requires high quality Climate Data Records (CDRs) of ECVs [21,22]. It is well recognized that satellite data often contain uncertainties caused by biases in sensors and retrieval algorithms [23], as well as inconsistencies between consecutive satellite missions with the same sensors, or between different sensors aiming at the same ECVs.

Serrat-Capdevila et al. [24] evaluated the performance of three satellite precipitation products over Africa (i.e., TRMM-TMPA, PERSIANN, and CMORPH), using the GPCP-1dd as a reference dataset for years 2001 to 2013. They identified different types of errors for each season as a function of spatial classification (latitudinal bands, climatic zones, and topography) as well as its relationship with the Intertropical Convergence Zone (ITCZ) and the East African Monsoon. A bias correction based on these identified errors were implemented to correct the satellite precipitation products. The bias-corrected precipitation products can follow the position of the ITCZ oscillating seasonally over the equator, illustrating that the performance of satellite precipitation products can be improved substantially after taking into account different types of errors.

To address the challenge of deriving soil moisture (SM) data with a complete coverage of the Tibetan Plateau (TP) for an extended period of time for climate change studies, Zeng et al. [25] combined satellite-observed, model-simulated, and in situ measured SM over the Tibetan Plateau. The in situ SM networks, combined with the classification of climate zones over the TP, were used to produce the in situ measured soil moisture climatology at the plateau scale, which was subsequently used to scale the model-simulated SM. The bias-corrected, model-simulated SM were then used to scale the satellite SM products. The three climatology-scaled SM products were blended objectively, by applying the triple collocation and least squares method. The final blended SM can replicate the SM dynamics across different climatic zones, from sub-humid regions to semi-arid and arid regions over the TP. This approach indicates the need to constrain model-simulated SM estimates with in situ measurements before their further application in scaling climatology of satellite SM products.

Song and Jia [26] used the theory of Apparent Thermal Inertia (ATI), under bare surface or sparse vegetation-covered land surface, to downscale FengYun-3B (FY-3B) soil moisture product from 25-km to 1-km spatial resolution. This downscaling was achieved by establishing the relationship between soil moisture and the ATI, the coefficients of which were obtained directly from 25-km FY-3B SM product and the ATI derived from MODIS data. The downscaled SM showed promising results when compared with the in situ SM measurements. They concluded that the accuracy of the FY-3B 25-km SM product determines the reliability of the coefficients of regression between SM and ATI, and that the proposed method is more applicable to areas with NDVI values smaller than 0.4 . This limitation is mainly due to the fact that MODIS can only sense vegetation conditions, which reflect more the root 
zone soil water content than the surface soil moisture. The use of high resolution SAR data was further suggested to downscale SM over densely vegetated areas.

From the perspective of radiative transfer theory, Lv et al. [27] discussed how to determine the optimal mounting depth of soil moisture and soil temperature (SMST) sensors, for calculating soil effective temperature $\left(T_{\text {eff }}\right)$ from satellite microwave sensors at the L-band, based on Lv's multilayer $T_{\text {eff }}$ scheme [28,29]. It was found that, on average, nearly $20 \%$ of the $T_{\text {eff }}$ signal cannot be captured by the Maqu in situ SMST network, using the currently assumed common installation configurations (i.e., $5 \mathrm{~cm}, 10 \mathrm{~cm}, 20 \mathrm{~cm}, 40 \mathrm{~cm}$, and $80 \mathrm{~cm}$ ). Furthermore, they identified the optimal mounting depths for the SMST observation pair as $5 \mathrm{~cm}$ and $20 \mathrm{~cm}$ by calculating $T_{\text {eff }}$ at the center station in the Maqu Network. The findings can help to establish an optimal SMST network and improve the representativeness of the existing networks regarding the calculation of $T_{\text {eff. }}$.

Zhou et al. [30] explored the linkage between soil moisture and the Qinghai-Xizang Plateau monsoon evolution, and proposed a new plateau monsoon index (ZPMI). The ZPMI was compared with the existing Plateau Monsoon Indices (PMI): the Traditional Plateau Monsoon Index (TPMI), the Dynamic Plateau Monsoon Index (DPMI), and the QPMI (i.e., PMI developed by Qi et al.). The results show that the onset and retreat of plateau monsoons determined by the TPMI are approximately 1-2 months earlier than those of the ZPMI and DPMI, while the ZPMI can better reflect seasonal and inter-annual variations in precipitation over the plateau. They found that the plateau summer and winter monsoons have similar inter-annual and inter-decadal variation characteristics and show a rising trend, although the increasing trend of the summer monsoon is more significant. The analysis of ZPMI and SM in April and May revealed that when the SM over the central and eastern plateau is higher than normal, the plateau summer monsoon is stronger, and vice versa.

Phan et al. [31] assessed the orographic variability in glacial thickness changes at the Tibetan Plateau using ICESat laser altimetry, in combination with the SRTM DEM and the GLIMS glacier mask. Using the ICESat elevations acquired over terrain with a slope below $20^{\circ}$ and a roughness at the footprint scale below $15 \mathrm{~m}$, they identified 90 glaciated areas and investigated their changes. The results show that most of observed glaciated areas over the Tibetan Plateau are thinning, except for some glaciers in the northwest. Particularly, most north-facing glaciers increase in thickness. They concluded that glacial thickness changes depend strongly on the relative position in a mountain range.

Due to satellite configuration and errors from spatial sampling, daily time series of microwave radiometer data obtained in one-orbit direction are suffering observation gaps. On the other hand, such time series carry information about the surface and atmosphere signal including emittance and attenuation. Shang et al. [32] developed the Time Series Analysis Procedure (TSAP) to extract the surface signal from the noisy time series, based on the properties of the Discrete Fourier Transform (DFT). In particular, the Polarization Difference Brightness Temperature (PDBT) at $37 \mathrm{GHz}$ data were used to explain the implementation of TSAP. The use of PDBT is beneficial for noise reduction, as the PDBT range between dryland and open water is about $20 \mathrm{k}$. Furthermore, since the PDBT at $37 \mathrm{GHz}$ is mainly attenuated by hydrometeors that yield precipitation, the time series of rain-gauge data can help to reveal the spectral feature of the atmospheric signal. Thus, the spectral features of the surface signal were identified in the PDBT time series with the help of the rain-gauge data, as well as the Harmonic Analysis of Time Series (HANTS) algorithm correcting for atmospheric influence.

\section{Concluding Remarks}

The presented results are highlights of the recent advancements in Earth observation of land surface processes and interactions. Nevertheless, they represent the latest scientific results well and show how, from the challenges related to the first HCMM images, remote sensing has developed into a matured technology, capable of providing sophisticated methods to analyze the enormous data flow of the Sentinels to meet the information demands of diverse applications. 
Author Contributions: Z.S. initiated, conceptualized and designed the framework; Z.V. initiated the special issue and invited contributions; Z.S., Z.V. and Y.Z. edited the special issue; Y.Z. drafted the editorial paper; Z.S. and Z.V. contributed to revisions and comments.

Conflicts of Interest: The authors declare no conflict of interest.

\section{References}

1. GEWEX. GEWEX's Vision and Mission. 2016. Available online: http://www.gewex.org/about/science/ vision-and-mission/ (accessed on 18 November 2016).

2. The National Aeronautics and Space Administration (NASA). Themal infrared data from heat capacity mapping mission. Remote Sens. Environ. 1981, 11, 77-79.

3. Committee on International Space Programs; National Research Council; European Space Science Committee; European Science Foundation. U.S.-European Collaboration in Space Science; National Academies Press: Washington, DC, USA, 1998.

4. Malenovský, Z.; Rott, H.; Cihlar, J.; Schaepman, M.E.; García-Santos, G.; Fernandes, R.; Berger, M. Sentinels for science: Potential of sentinel-1, -2 , and -3 missions for scientific observations of ocean, cryosphere, and land. Remote Sens. Environ. 2012, 120, 91-101. [CrossRef]

5. Su, Z.; He, Y.; Dong, X.; Wang, L. Drought monitoring and assessment using remote sensing. In Remote Sensing of Hydrological Extremes; Lakshimi, V., Ed.; Springer: Berlin, Germany, 2016; Chapter 8.

6. Su, Z.; Yacob, A.; Wen, J.; Roerink, G.J.; He, Y.; Gao, B.; Boogaard, H.L.; van Diepen, C. Assessing relative soil moisture with remote sensing data: Theory, experimental validation, and application to drought monitoring over the North China plain. Phys. Chem. Earth 2003, 28, 89-101. [CrossRef]

7. Bayat, B.; van der Tol, C.; Verhoef, W. Remote sensing of grass response to drought stress using spectroscopic techniques and canopy reflectance model inversion. Remote Sens. 2016, 8, 557. [CrossRef]

8. Wang, R.; Cherkauer, K.; Bowling, L. Corn response to climate stress detected with satellite-based NDVI time series. Remote Sens. 2016, 8, 269. [CrossRef]

9. Van Hoek, M.; Jia, L.; Zhou, J.; Zheng, C.; Menenti, M. Early drought detection by spectral analysis of satellite time series of precipitation and normalized difference vegetation index (NDVI). Remote Sens. 2016, 8, 422. [CrossRef]

10. Navarro, A.; Rolim, J.; Miguel, I.; Catalão, J.; Silva, J.; Painho, M.; Vekerdy, Z. Crop monitoring based on SPOT-5 take-5 and Sentinel-1A data for the estimation of crop water requirements. Remote Sens. 2016, 8, 525. [CrossRef]

11. McCabe, M.F.; Ershadi, A.; Jimenez, C.; Miralles, D.G.; Michel, D.; Wood, E.F. The GEWEX LandFlux project: Evaluation of model evaporation using tower-based and globally gridded forcing data. Geosci. Model Dev. 2016, 9, 283-305. [CrossRef]

12. Chen, X.; Su, Z.; Ma, Y.; Yang, K.; Wang, B. Estimation of surface energy fluxes under complex terrain of Mt. Qomolangma over the Tibetan Plateau. Hydrol. Earth Syst. Sci. 2013, 17, 1607-1618. [CrossRef]

13. Chen, X.; Su, Z.; Ma, Y.; Liu, S.; Yu, Q.; Xu, Z. Development of a 10-year (2001-2010) 0.1 data set of land-surface energy balance for mainland china. Atmos. Chem. Phys. 2014, 14, 13097-13117. [CrossRef]

14. Yu, L.; Zeng, Y.; Su, Z.; Cai, H.; Zheng, Z. The effect of different evapotranspiration methods on portraying soil water dynamics and et partitioning in a semi-arid environment in northwest China. Hydrol. Earth Syst. Sci. 2016, 20, 975-990. [CrossRef]

15. Faivre, R.; Colin, J.; Menenti, M. Evaluation of methods for aerodynamic roughness length retrieval from very high-resolution imaging lidar observations over the Heihe Basin in China. Remote Sens. 2017, 9, 63. [CrossRef]

16. Su, Z. The surface energy balance system (SEBS) for estimation of turbulent heat fluxes. Hydrol. Earth Syst. Sci. 2002, 6, 85-100. [CrossRef]

17. Roupioz, L.; Jia, L.; Nerry, F.; Menenti, M. Estimation of daily solar radiation budget at kilometer resolution over the Tibetan Plateau by integrating MODIS data products and a DEM. Remote Sens. 2016, 8, 504. [CrossRef]

18. Lin, X.; Zhang, W.; Huang, Y.; Sun, W.; Han, P.; Yu, L.; Sun, F. Empirical estimation of near-surface air temperature in China from MODIS LST data by considering physiographic features. Remote Sens. 2016, 8, 629. [CrossRef] 
19. Wu, Y.; de Graaf, M.; Menenti, M. The sensitivity of aod retrieval to aerosol type and vertical distribution over land with MODIS data. Remote Sens. 2016, 8, 765. [CrossRef]

20. Abdelrady, A.; Timmermans, J.; Vekerdy, Z.; Salama, M. Surface energy balance of fresh and saline waters: AquaSEBS. Remote Sens. 2016, 8, 583. [CrossRef]

21. Zeng, Y.; Su, Z.; Calvet, J.C.; Manninen, T.; Swinnen, E.; Schulz, J.; Roebeling, R.; Poli, P.; Tan, D.; Riihelä, A.; et al. Analysis of current validation practices in Europe for space-based climate data records of essential climate variables. Int. J. Appl. Earth Obs. Geoinf. 2015, 42, 150-161. [CrossRef]

22. Su, Z.; Timmermans, J.; Zeng, Y.; Schulz, J.; John, V.O.; Roebeling, R.; Poli, P.; Tan, D.; Kaspar, F.; Kaiser-Weiss, A.; et al. An overview of European efforts in generating climate data records. Bull. Am. Meteorol. Soc. 2017. under review.

23. Su, Z.; de Rosnay, P.; Wen, J.; Wang, L.; Zeng, Y. Evaluation of ECMWF's soil moisture analyses using observations on the Tibetan Plateau. J. Geophys. Res. 2013, 118, 5304-5318. [CrossRef]

24. Serrat-Capdevila, A.; Merino, M.; Valdes, J.; Durcik, M. Evaluation of the performance of three satellite precipitation products over Africa. Remote Sens. 2016, 8, 836. [CrossRef]

25. Zeng, Y.; Su, Z.; van der Velde, R.; Wang, L.; Xu, K.; Wang, X.; Wen, J. Blending satellite observed, model simulated, and In Situ measured soil moisture over Tibetan Plateau. Remote Sens. 2016, 8, 268. [CrossRef]

26. Song, C.; Jia, L. A method for downscaling Fengyun-3b soil moisture based on apparent thermal inertia. Remote Sens. 2016, 8, 703. [CrossRef]

27. Lv, S.; Zeng, Y.; Wen, J.; Zheng, D.; Su, Z. Determination of the optimal mounting depth for calculating effective soil temperature at L-band: Maqu case. Remote Sens. 2016, 8, 476. [CrossRef]

28. Lv, S.; Wen, J.; Zeng, Y.; Tian, H.; Su, Z. An improved two-layer algorithm for estimating effective soil temperature in microwave radiometry using in situ temperature and soil moisture measurements. Remote Sens. Environ. 2014, 152, 356-363. [CrossRef]

29. Lv, S.; Zeng, Y.; Wen, J.; Su, Z. A reappraisal of global soil effective temperature schemes. Remote Sens. Environ. 2016, 183, 144-153. [CrossRef]

30. Zhou, J.; Wen, J.; Wang, X.; Jia, D.; Chen, J. Analysis of the Qinghai-Xizang Plateau monsoon evolution and its linkages with soil moisture. Remote Sens. 2016, 8, 493. [CrossRef]

31. Phan, V.; Lindenbergh, R.; Menenti, M. Assessing orographic variability in glacial thickness changes at the Tibetan Plateau using icesat laser altimetry. Remote Sens. 2017, 9, 160. [CrossRef]

32. Shang, H.; Jia, L.; Menenti, M. Modeling and reconstruction of time series of passive microwave data by discrete Fourier transform guided filtering and harmonic analysis. Remote Sens. 2016, 8, 970. [CrossRef] 